\title{
Combination Therapy Consisting of Ethanol and Radiofrequency Ablation for Predominantly Cystic Thyroid Nodules
}

\author{
H.M. Yoon, J.H. Baek, J.H. Lee, E.J. Ha, J.K. Kim, J.H. Yoon, and W.B. Kim
}

\begin{abstract}
SUMMARY: Predominantly cystic thyroid nodules are often aspirated before radiofrequency ablation to enhance its efficacy; however internal bleeding during the aspiration is a problem. We evaluated the feasibility and safety of ethanol ablation to control internal bleeding that occurred during preparatory aspiration. Between September 2010 and August 2011, 11 of 40 predominantly cystic nodules bled internally during fluid aspiration before radiofrequency ablation. To control the bleeding, $99 \%$ ethanol was injected. The efficacy of ethanol in controlling bleeding, final nodule volume and complications were assessed. Control of the bleeding by ethanol ablation and subsequent radiofrequency ablation was feasible in all patients. Ninety-one percent (10/11) could be treated in 1 session. The mean nodule volume dropped from 17.1 to $4.3 \mathrm{~mL}(P<.018)$. There were no major complications. Ethanol ablation and radiofrequency ablation combination therapy is a feasible and safe technique for treating predominantly cystic thyroid nodules that exhibit internal bleeding during preparatory aspiration.
\end{abstract}

ABBREVIATIONS: $E A=$ ethanol ablation; $R F=$ radio-frequency; $U S=$ ultrasound

B enign nodular thyroid disease is common, and $15 \%-25 \%$ of solitary nodules are cystic or predominantly cystic on sonography. ${ }^{1}$ Most cystic lesions are considered caused by the hemorrhage and subsequent degeneration of pre-existing nodules. ${ }^{2}$ In patients with cosmetic or symptomatic problems, the initial procedure is the simple aspiration of the cystic portion; this reduces the cyst volume and aids in specific diagnosis, but it is associated with a high recurrence rate of up to $80 \% .{ }^{3,4}$ For recurrent cases after aspiration, ethanol ablation (EA) has been attempted with good results. ${ }^{5,6}$

Recently, radiofrequency (RF) ablation has been used to treat benign thyroid nodules with a low complication rate, ${ }^{7-12}$ including thyroid nodules with a cystic portion ${ }^{6,8}$ and recurrent thyroid cancers. ${ }^{13}$ Although EA is effective for treating cystic and predominantly cystic nodules, $5 \%-25 \%$ of patients are refractory to EA.

Received April 3, 2013; accepted after revision June 7.

From the Departments of Radiology and Research Institute of Radiology (H.M.Y., J.H.B., J.H.L., E.J.H.), Surgery (J.H.Y.), and Endocrinology and Metabolism (W.B.K.), University of Ulsan College of Medicine, Asan Medical Center, Seoul, Korea; and Department of Radiology (J.K.K.), Chung-Ang University College of Medicine, Seoul, Korea.

We declare that we have no proprietary, commercial, or financial interests that could be construed to have inappropriately influenced this study.

Please address correspondence to Jung Hwan Baek, MD, Department of Radiology and Research Institute of Radiology, University of Ulsan College of Medicine, Asan Medical Center, 86 Asanbyeongwon-Gil, Songpa-Gu, Seoul 138-736, Korea; e-mail address: radbaek@naver.com

$\checkmark$ Indicates article with supplemental on-line video.

http://dx.doi.org/10.3174/ajnr.A3701
For those refractory cases, EA has been re-attempted, but with a marked decline in subsequent efficacy. ${ }^{14,15}$ EA has been used as a first-line treatment for cystic thyroid nodules ${ }^{6,16}$; however EA as a first-line treatment is debatable for predominantly cystic thyroid nodules ${ }^{15,17,18}$ because the recurrence rate is $>50 \%$ in these nodules with solid components of $>20 \%$.

When treating predominantly cystic nodules by thermal ablation, it is recommended that the internal fluid content be aspirated before RF or laser ablation ${ }^{6,19}$ because it is easier to treat decompressed small nodules than larger ones. ${ }^{20}$ Internal hemorrhage can develop during the aspiration, however, and this bleeding enlarges the nodule volume and has a heat sink effect that could affect the efficacy of RF ablation.

In our clinic, predominantly cystic thyroid nodules that bled internally after aspiration were injected with ethanol, after which they were subjected to RF ablation. The aim of this study was to evaluate the feasibility and safety of EA in controlling internal bleeding during aspiration of the internal fluid of predominantly cystic thyroid nodules before RF ablation.

\section{MATERIALS AND METHODS \\ Patients}

This retrospective study was approved by our institutional review board. Informed consent for procedures was obtained from all patients before each procedure.

Between September 2010 and August 2011, one hundred thirty-one RF ablations of benign thyroid nodules were per- 
formed in Asan Medical Center. Forty of these cases involved patients with predominantly cystic nodules whose internal fluid was aspirated before RF ablation. In 11 of these patients, each of whom had 1 nodule, the cysts bled internally during the aspiration of internal fluid, and they were enrolled in this study. We enrolled 3 men and 8 women with a mean age of 47.1 years (range, 30-69 years). All patients fulfilled the following criteria: 1) The cystic portion of the nodule exceeded $50 \%$ of the nodule volume, 2 ) there were thyroid nodule-related pressure symptoms or cosmetic problems, 3) the serum thyroid hormone and thyrotropin levels were within normal limits, 4) 2 separate ultrasound (US)guided fine-needle aspirations led to a cytologically confirmed diagnosis of a benign lesion, and 5) there were no malignant features on the US examination. ${ }^{21-23}$

\section{Preablation Assessment}

The US and US-guided fine-needle aspirations were performed by 2 radiologists (J.H.B. and J.H.L., who had 17 and 13 years of thyroid US experience, respectively). The US examinations were performed by using 1 of 2 US systems equipped with a linear high-frequency probe (5-14 MHz), namely, iU22 U (Philips Healthcare, Bothell, Washington) or EUB-7500 U (Hitachi Medical Systems, Tokyo, Japan). The size, volume, amount of solid component, and vascularity of each nodule were assessed. The 3 orthogonal diameters of each nodule (the largest diameter and the 2 diameters perpendicular to it) were measured, and the volume of each nodule was calculated by using the following equation: $\mathrm{V}=\pi \mathrm{abc} / 6$, where $\mathrm{V}$ is volume, $\mathrm{a}$ is the largest diameter, and $\mathrm{b}$ and $c$ are the 2 perpendicular diameters. ${ }^{8,13,24}$ Under US guidance, 1 of the 2 radiologists performed fine-needle aspiration on the solid component of each nodule. At enrollment, the patients were asked to rate their symptom score on a $10-\mathrm{cm}$ Visual Analog Scale $(0-10)$. The physicians recorded a cosmetic grade (1, no palpable mass; 2, a palpable mass but no cosmetic problem; 3 , cosmetic problem on swallowing only; and 4, readily detected cosmetic problem). ${ }^{6,25,26}$

\section{Procedure}

All procedures were performed under US guidance. Intravenous sedatives or analgesics were not used before or during the procedure. The patients were placed in a supine position with mild neck extension. After skin sterilization and anesthesia with $2 \%$ lidocaine at the puncture site, a 16- or 18-ga needle was inserted into the cystic portion of the thyroid nodules through the isthmic area (this is the so-called transisthmic approach) to prevent leakage of fluid or ethanol. ${ }^{6,18,25}$ After the needle tip was placed into the cystic portion, as much of the internal fluid as possible was aspirated. If active bleeding was detected during the aspiration of the internal fluid, the aspiration was stopped and 99\% ethanol was injected slowly into the cystic space to control the bleeding (On-line Video). The injected volume of ethanol corresponded to approximately $50 \%$ of the aspirated fluid volume. After 2 minutes of ethanol retention, as much of the injected ethanol as possible was removed. ${ }^{18}$ After real-time US confirmed that the bleeding had stopped, RF ablation was initiated. On the basis of previous experience, the RF ablation was performed by using a transisthmic approach and the moving-shot tech- nique. ${ }^{6-8,10,15,17,25-27}$ For this, an 18-ga 7-cm-long monopolar modified internally cooled electrode (Well-Point RF electrode; Taewoong Medical, Kimpo, Korea or VIVA; STARmed, Gyeonggi, Korea) with a $1-$ or $1.5-\mathrm{cm}$ active tip and a $200-\mathrm{W}$ RF generator (VIVA RF Generator; STARmed) was used.

When RF ablation was started with the 11 patients, echogenic bubbles developed much faster than would normally occur. This phenomenon was due to the remnants of ethanol in the nodule that had diffused into the septate cystic portion (On-line Video). The moving-shot technique used for thyroid RF ablation $^{7,8,10,28-30}$ was first proposed by Baek et al, ${ }^{26}$ who suggested that the thyroid nodule should be divided into multiple conceptual ablation units that would each undergo RF ablation; this was achieved by moving the electrode tip. Because the conceptual units are smaller at the periphery of the nodule and larger in the center of the nodule, the electrode tip was initially positioned in the deepest, most remote portion of the nodule where there were no disturbances caused by microbubbles; this positioning facilitated the monitoring of the electrode tip. RF ablation was terminated when all conceptual units of the targeted nodule had changed into a transient hyperechoic zone. Adverse events during and immediately after the procedure were recorded. After RF ablation, the patient was observed for 1-2 hours in the hospital.

\section{Follow-Up and Analysis}

At 1, 6, and 12 months after RF ablation and every 6-12 months thereafter, the clinical symptoms and cosmetic problems of all patients were re-evaluated. US examinations were also performed; changes in the amounts of the cystic portion, the internal vascularity, the echogenicity, the size, and the volume of the nodules were recorded. The efficacy of RF ablation was determined by measuring the volume reduction of the treated thyroid nodules and by assessing changes in the symptoms and cosmetic problems. Therapeutic success was defined as a nodule volume reduction $>50 \%$. Adverse events during the follow-up period were also recorded. Recurrence was defined as an increase in nodule volume by $>50 \%$ relative to the volume recorded by US previously. $^{21}$

\section{Statistical Analysis}

All statistical analyses were performed by using the Statistical Package for the Social Sciences for Windows (Version 18.0; IBM, Armonk, New York). The Wilcoxon signed rank test was used to evaluate the efficacy (changes in the largest diameter, the volume, and the cosmetic and symptom scores) of RF ablation at the 1-month, 6-month, and last follow-up visits.

\section{RESULTS}

After EA, the active bleeding stopped in all patients and US confirmed that there was no blood collection within the thyroid nodule. The efficacy of RF ablation is summarized in the Table. The mean follow-up period was $11.4 \pm 6.7$ months (range, 6-24 months). The mean largest diameter decreased from $4.1 \pm 1.3 \mathrm{~cm}$ (range, $2.4-7.1 \mathrm{~cm}$ ) before treatment to $2.3 \pm 0.6 \mathrm{~cm}$ (range, $1.3-3.0 \mathrm{~cm})$ at the last follow-up $(P=.003)$, and the mean volume dropped from $17.1 \pm 16.9 \mathrm{~mL}$ (range, $2.9-59.0 \mathrm{~mL}$ ) to $2.6 \pm 2.1$ 
$\mathrm{mL}$ (range, $0.2-6.9 \mathrm{~mL})$ at the last follow-up $(P=.005)$. At the 1-month, 6-month, and last follow-up visits, the mean volume reduction percentages were $52.9 \%, 75.6 \%$, and $81.0 \%$, respectively. Therapeutic success was achieved in all patients. The mean cosmetic score decreased from 4.0 before treatment to $2.8 \pm 1.0$ (range, $1-4)$ at the last follow-up $(P=.01)$. The mean symptom score dropped from $2.7 \pm 1.5$ (range, $1-5$ ) before treatment to $1.1 \pm 1.0$ (range, $0-4$ ) at the last follow-up $(P=.011)$. The follow-up US examinations indicated welltreated nodules that no longer had a cystic portion and whose echogenicity of the solid portion and intranodular vascularity was decreasing (Fig 1).

The mean number of ablation sessions was $1.2 \pm 0.6$ (range, $1-3)$ : Ten patients had 1 session, while the remaining patient had 3 sessions. The latter patient had a large initial thyroid nodule

Efficacy of ethanol and RF ablation combination therapy ${ }^{a}$

\begin{tabular}{lccc}
\hline & Initial & Last Follow-Up & $\boldsymbol{P}$ Value \\
\hline Largest diameter $(\mathrm{cm})$ & $4.1 \pm 1.3$ & $2.3 \pm 0.6$ & .003 \\
Volume $(\mathrm{mL})$ & $17.1 \pm 16.9$ & $2.6 \pm 2.1$ & .005 \\
Cosmetic score & $4.0 \pm 0$ & $2.8 \pm 1.0$ & .01 \\
Symptom score & $2.7 \pm 1.5$ & $1.1 \pm 1.0$ & .011 \\
Volume reduction $(\%)$ & - & 81 & - \\
Therapeutic success $(\%)^{\mathrm{b}}$ & - & 100 & - \\
\hline
\end{tabular}

a Values are means.

b Therapeutic success is volume reduction $>50 \%$.
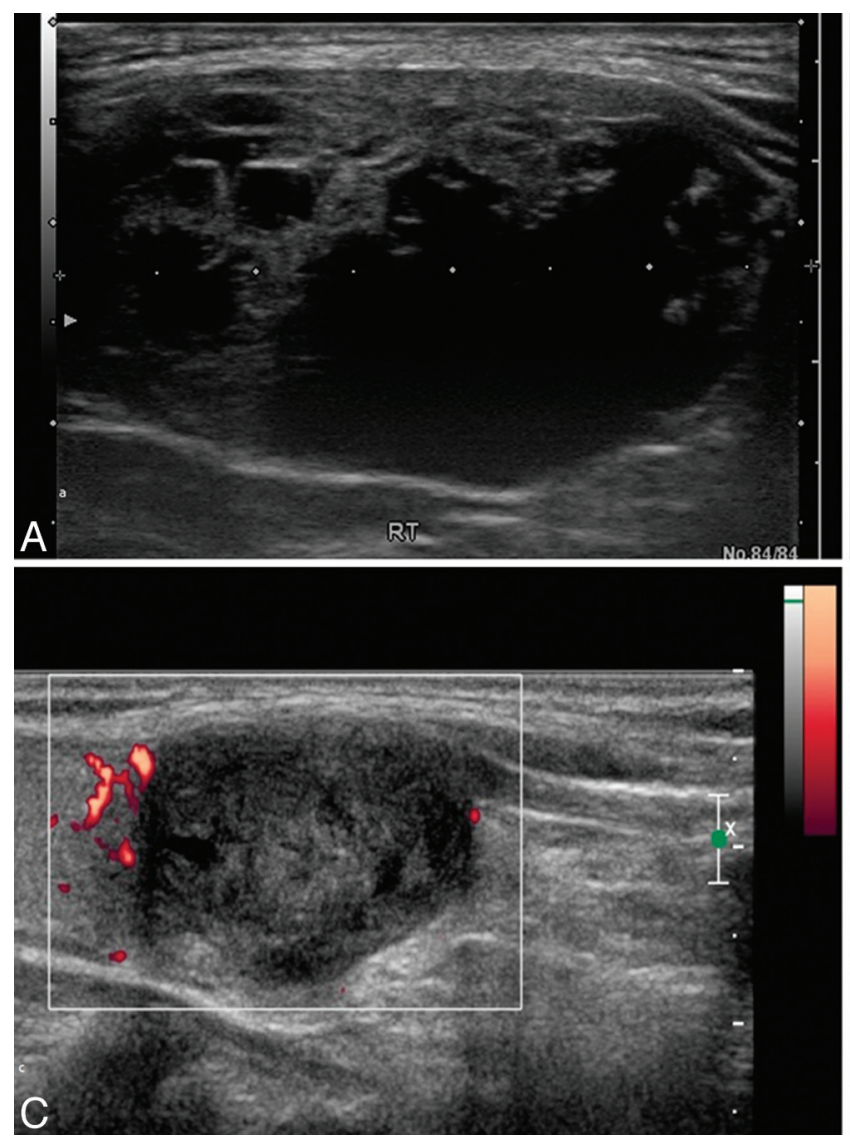

volume of $37.3 \mathrm{~mL}$. The mean ablation time and power were $6.3 \pm$ 3.0 minutes (range, 3-12 minutes) and $57.3 \pm 24.9 \mathrm{~W}$ (range, $30-120 \mathrm{~W})$, respectively. The mean total energy deposition was $21,218.2 \pm 11,523.7 \mathrm{~J}$ (range, 7800-36,000 J). The mean energy delivered per milliliter of pretreatment nodule volume was $2013.3 \pm 1228.3 \mathrm{~J}$ (range, 684.2-4230.8 J). The mean volume of aspirated internal fluid was $8.8 \pm 9.3 \mathrm{~mL}$ (range, $2-35 \mathrm{~mL}$ ), while the mean amount of ethanol that was injected was $5.1 \pm 5.7 \mathrm{~mL}$ (range, 1-20 mL).

There were no major complications, such as voice changes, skin burn, hematoma, esophageal injury, tracheal injury, or infection, either during the procedure or in the follow-up period. During RF ablation, most patients reported pain and a sensation of heat in the neck that radiated to the head, shoulders, teeth, and chest. The symptoms were relieved by reducing the RF power or stopping the ablation for several seconds. All patients tolerated the RF ablation procedure well.

\section{DISCUSSION}

The present study showed that EA effectively controlled the postaspiration hemorrhage in all patients. The RF ablation, after bleeding control was achieved, significantly reduced the nodule volume and relieved the symptomatic and cosmetic problems. In addition, $91 \%(10 / 11)$ of the patients could be treated by $1 \mathrm{RF}$ session, and there were no recurrences during the follow-up pe-
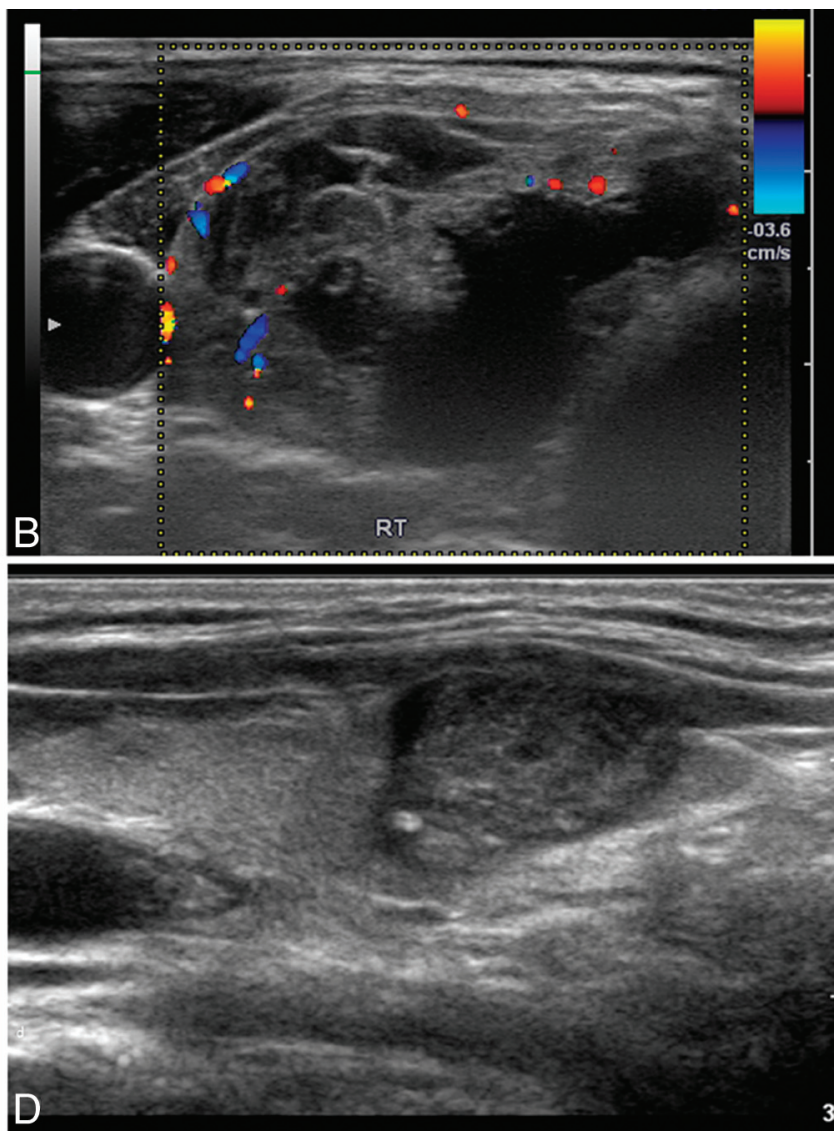

FIG 1. A 59-year-old female patient who presented with a bulge in the neck. A, Transverse US images at presentation show a thyroid nodule with a cystic portion in the right thyroid gland. The initial volume of the nodule was $11.4 \mathrm{~mL}$. B, On Doppler US, increased vascularity in the solid portion of the nodule was also noted. $C$ and $D$, After active bleeding was controlled by EA and RF ablation was performed, the volume of the ablated nodule decreased gradually to 2.8 and $0.9 \mathrm{~mL}$ at the 6- and 12-month follow-up US examinations, respectively. At the 12-month follow-up visit, the volume had been reduced by approximately $92 \%$. 
riod. There were also no complications that related to the EA or RF ablation.

Initial nodule volume can be a risk factor for poor volume reduction by $\mathrm{RF}$ and the need for additional RF treatment sessions. Huh et $\mathrm{al}^{20}$ reported that an initial nodule volume larger than $20 \mathrm{~mL}$ required additional $\mathrm{RF}$ ablation to achieve satisfactory clinical results. Moreover, Jeong et $\mathrm{al}^{8}$ reported that thyroid nodules with a mean volume of $6.1 \mathrm{~mL}$ required an average of 1.4 treatment sessions, while Lim et $\mathrm{al}^{31}$ reported that thyroid nodules with a mean volume of $9.8 \mathrm{~mL}$ required 2.2 treatment sessions on average. These results indicate that smaller thyroid nodules can be treated with fewer sessions. In the present study, the mean nodule volume was larger $(17.1 \mathrm{~mL})$ than the mean volumes in the other RF studies (6.1-9.8 mL). ${ }^{8,31}$ Nevertheless, 91\% (10/ 11 ) of patients could be treated in a single RF session; in addition, there were no recurrences during the mean follow-up period of 11.4 months. As a result, the mean treatment session number in this study was smaller (1.2) than the numbers in other studies (1.4-2.2). The present study differed from the preceding studies in that the internal fluid was aspirated to reduce the nodule volume with the aim of reducing the number of treatment sessions. The results indicate that this approach was successful. However, active bleeding can be triggered by the aspiration, and this can create an important technical problem: It can cause sudden enlargement of the thyroid nodule and the heat sink effect of the blood can make RF ablation ineffective. The present study showed that EA successfully controlled active bleeding during aspiration and that nodule volume was effectively reduced before RF ablation.

The reduction in nodule volume after RF ablation has been found to range from $33 \%$ to $58 \%$ at 1 month and from $51 \%$ to $92 \%$ at 6 months. ${ }^{26}$ Jeong et $\mathrm{al}^{8}$ reported that after a mean follow-up period of 12 months, the mean volume reduction was $84.1 \%$ and that $70.2 \%$ of the nodules could be treated by a single treatment session. In the present study, the mean follow-up period was $11.4 \pm 6.7$ months, the mean volume reduction was $81.0 \%$, and $91 \%(10 / 11)$ of the nodules could be treated by a single session. Therefore, our results are comparable with those of previous studies with fewer treatment sessions. In addition, there was $100 \%$ technical success and no major complications.

RF ablation combined with EA has been used for hepatocellular carcinomas in high-risk locations, and 2 studies have shown that this combination is more effective and safe than RF ablation alone. $^{32,33}$ In these studies, the principal role of ethanol was to induce a larger necrotic area and to minimize complications. ${ }^{34,35}$ To our knowledge, the present study is the first to examine the efficacy of the combination of these 2 modalities in treating predominantly cystic thyroid nodules.

The present study has several limitations. First, it had a retrospective design, but a standard technique was used to control active bleeding during the RF ablation. Second, the number of cases was small, and the follow-up period was short. Third, there was no control group. Further prospective studies are required to verify the value of the current study.

\section{CONCLUSIONS}

EA is a feasible and safe technique for controlling the active bleeding of predominantly cystic thyroid nodules that can occur when internal fluid is aspirated before RF ablation, allowing RF ablation to proceed in a single session in most instances.

\section{REFERENCES}

1. Mazzaferri EL. An overview of the management of papillary and follicular thyroid carcinoma. Thyroid 1999;9:421-27

2. Yasuda K, Ozaki O, Sugino K, et al. Treatment of cystic lesions of the thyroid by ethanol instillation. World J Surg 1992;16:958-61

3. Cho YS, Lee HK, Ahn IM, et al. Sonographically guided ethanol sclerotherapy for benign thyroid cysts: results in 22 patients. $A J R$ Am J Roentgenol 2000;174:213-16

4. Kim JH, Lee HK, Lee JH, et al. Efficacy of sonographically guided percutaneous ethanol injection for treatment of thyroid cysts versus solid thyroid nodules. AJR Am J Roentgenol 2003;180:1723-26

5. Zingrillo M, Torlontano M, Ghiggi MR, et al. Percutaneous ethanol injection of large thyroid cystic nodules. Thyroid 1996;6:403-08

6. Sung JY, Kim YS, Choi H, et al. Optimum first-line treatment technique for benign cystic thyroid nodules: ethanol ablation or radiofrequency ablation? AJR Am J Roentgenol 2011;196:W210-14

7. Baek JH, Moon WJ, Kim YS, et al. Radiofrequency ablation for the treatment of autonomously functioning thyroid nodules. World J Surg 2009;33:1971-77

8. Jeong WK, Baek JH, Rhim H, et al. Radiofrequency ablation of benign thyroid nodules: safety and imaging follow-up in 236 patients. Eur Radiol 2008;18:1244-50

9. Spiezia S, Garberoglio R, Milone F, et al. Thyroid nodules and related symptoms are stably controlled two years after radiofrequency thermal ablation. Thyroid 2009;19:219-25

10. Baek JH, Kim YS, Lee D, et al. Benign predominantly solid thyroid nodules: prospective study of efficacy of sonographically guided radiofrequency ablation versus control condition. AJR Am J Roentgenol 2010;194:1137-42

11. Deandrea M, Limone $P$, Basso E, et al. US-guided percutaneous radiofrequency thermal ablation for the treatment of solid benign hyperfunctioning or compressive thyroid nodules. Ultrasound Med Biol 2008;34:784-91

12. Baek JH, Lee JH, Sung JY, et al. Complications encountered in the treatment of benign thyroid nodules with US-guided radiofrequency ablation: a multicenter study. Radiology 2012;262:335-42

13. Baek JH, Kim YS, Sung JY, et al. Locoregional control of metastatic well-differentiated thyroid cancer by ultrasound-guided radiofrequency ablation. AJR Am J Roentgenol 2011;197:W331-36

14. Bennedbaek FN, Hegedus L. Treatment of recurrent thyroid cysts with ethanol: a randomized double-blind controlled trial. J Clin Endocrinol Metab 2003;88:5773-77

15. Lee JH, Kim YS, Lee D, et al. Radiofrequency ablation (RFA) of benign thyroid nodules in patients with incompletely resolved clinical problems after ethanol ablation (EA). World J Surg 2010;34:1488-93

16. Sung JY, Baek JH, Kim KS, et al. Single-session treatment of benign cystic thyroid nodules with ethanol versus radiofrequency ablation: a prospective randomized study. Radiology 2013;269:293-300

17. Jang SW, Baek JH, Kim JK, et al. How to manage the patients with unsatisfactory results after ethanol ablation for thyroid nodules: role of radiofrequency ablation. Eur J Radiol 2012;81:905-10

18. Kim YJ, Baek JH, Ha EJ, et al. Cystic versus predominantly cystic thyroid nodules: efficacy of ethanol ablation and analysis of related factors. Eur Radiol 2012;22:1573-78

19. Dossing H, Bennedbaek FN, Hegedus L. Beneficial effect of combined aspiration and interstitial laser therapy in patients with benign cystic thyroid nodules: a pilot study. $\mathrm{Br} J$ Radiol 2006;79:943-47

20. Huh JY, Baek JH, Choi H, et al. Symptomatic benign thyroid nodules: efficacy of additional radiofrequency ablation treat- 
ment session-prospective randomized study. Radiology 2012; 263:909-16

21. Moon WJ, Baek JH, Jung SL, et al. Ultrasonography and the ultrasound-based management of thyroid nodules: consensus statement and recommendations. Korean J Radiol 2011;12:1-14

22. Moon WJ, Jung SL, Lee JH, et al. Benign and malignant thyroid nodules: US differentiation-multicenter retrospective study. $\mathrm{Ra}$ diology 2008;247:762-70

23. Park JM, Choi Y, Kwag HJ. Partially cystic thyroid nodules: ultrasound findings of malignancy. Korean J Radiol 2012;13:530-35

24. Kim SM, Baek JH, Kim YS, et al. Efficacy and safety of ethanol ablation for thyroglossal duct cysts. AJNR Am J Neuroradiol 2011;32:306-09

25. Sung JY, Baek JH, Kim YS, et al. One-step ethanol ablation of viscous cystic thyroid nodules. AJR Am J Roentgenol 2008;191:1730-33

26. Baek JH, Lee JH, Valcavi R, et al. Thermal ablation for benign thyroid nodules: radiofrequency and laser. Korean $J$ Radiol 2011;12:525-40

27. Ha EJ, Baek JH, Lee JH. The efficacy and complications of radiofrequency ablation of thyroid nodules. Curr Opin Endocrinol Diabetes Obes 2011;18:310-14

28. Ha EJ, Baek JH, Lee JH, et al. Radiofrequency ablation of benign thyroid nodules does not affect thyroid function in patients with previous lobectomy. Thyroid 2013;23:289-93
29. Shin JE, Baek JH, Lee JH. Radiofrequency and ethanol ablation for the treatment of recurrent thyroid cancers: current status and challenges. Curr Opin Oncol 2013;25:14-19

30. Na DG, Lee JH, Jung SL, et al. Radiofrequency ablation of benign thyroid nodules and recurrent thyroid cancers: consensus statement and recommendations. Korean J Radiol 2012;13:117-25

31. Lim HK, Lee JH, Ha EJ, et al. Radiofrequency ablation of benign non-functioning thyroid nodules: 4-year follow-up results for 111 patients. Eur Radiol 2013;23:1044-49

32. Zhang YJ, Liang HH, Chen MS, et al. Hepatocellular carcinoma treated with radiofrequency ablation with or without ethanol injection: a prospective randomized trial. Radiology 2007;244: $599-607$

33. Ren $\mathrm{H}$, Liang $\mathrm{P}, \mathrm{Yu} \mathrm{X}$, et al. Treatment of liver tumours adjacent to hepatic hilum with percutaneous microwave ablation combined with ethanol injection: a pilot study. Int $J$ Hyperthermia 2011;27:249-54

34. Wong SN, Lin CJ, Lin CC, et al. Combined percutaneous radiofrequency ablation and ethanol injection for hepatocellular carcinoma in high-risk locations. AJR Am J Roentgenol 2008; 190:W187-95

35. Zhou P, Liu X, Li R, et al. Percutaneous coagulation therapy of hepatocellular carcinoma by combining microwave coagulation therapy and ethanol injection. Eur J Radiol 2009;71:338-42 